\title{
Analysis of Team Work Efficiency with a Special View of Kosova
}

\author{
Driton Fetahu
}

PhD. Candidate at European University of Tirana, Albania

\begin{abstract}
Recently, modern organizations have seen everything the introduction of team work to increase the efficiency of the entire organization. These work was attempted to contribute to the understanding of the team work efficiency phenomena the factor influencing her and checking the ways of her measurement. The test was carried out at the bank in Kosova, the four-member team of the Service Department companies and their clients. By analyzing the work efficiency of these four teams statistically determined teams do not differ by selfassessments work efficiency as well as satisfaction ratings of their clients' service which were taken as measures of operational efficiency by these four teams. Also, tall and consistent the results of self-assessment of efficiency and customer service satisfaction estimates are provided to high work efficiency for all four teams. In this paper efficiency is defined in the terms of productivity, the satisfaction of workers and clients, and the managers' rating as well it recommends monitoring all these criteria in order to get as complete a picture of the work as possible efficiency of teams in organizations.
\end{abstract}

Keywords: teams, efficiency of timal work, landscape, clients with usage.

\section{Introduction}

\subsection{Teams in Organizations}

Still in 1911, American engineer Taylor first tries to rationalize human work

achieving the maximum workflow in as short a time. Taylor's is the foundation the idea that better organization of work and management can increase efficiency. People should be considered part of the organization and should be treated accordingly as to how much are useful for organization (Rot, 1983). Taking the best and most enjoyable way to work workers, raise the rational organization of movement and production tools to maximum Taylor managed to reduce the required number of workers and increase productivity.

What he has been justifiably criticized today is too much to take into account the role of a man in work, and as much as he took, was far less in favor of the worker, and much more the benefit of the employer. There has been a rise in unemployment, for workers who are the rest of the business earnings increased at a minimum compared to the increase in productivity and used for the employer (Petz, 1985).

The turn of the man's role in the organization took place after the so- Hawthorne experiment. Between 1924 and 1930 Elton Mayo and Fritz Roethisberger made the Hawthorne plants from Western Electric from Chicago a series of studies aimed at answering questions about how physical activity works worker environment. The results showed that the work force of the workers included in the experiments have grown steadily regardless of the favorable or unfavorable conditions of the physical

\section{environment. Intense interviews with workers have shown behavior and feelings}

worker in close relationship, that groups have a strong influence on individual behavior and are grouped the standards are very effective in setting up a workforce. It was found that money in to a lesser extent it determines work performance in relation to group standards and individual a sense of worker safety (Robbins, 1992). One of the most important benefits of this he experimented with what he - albeit unintentionally - pointed to the role the groups have in organizations. It has also stimulated the avalanche of later research in this area they focused on studying an individual in a group and a group of organizations (Petz, 1985). 
Psychological characteristics of working organizations and its parts, working groups, in detail have been studied as the main area of social psychology at work, within the framework psychology of work and organizational psychology.

The working group represents a structure with special characteristics and not just a sum individuals. According to the definition of a working group provided by Schein (1965) "a psychological group there are a number of people who are in mutual interaction, aware of each other and themselves they perceive themselves as a group "(according to Petz, 1985, $p$. 195).

It is characteristic for small workgroups in organizations that their goal is there is the production of social goods. The interaction of the members is based on a co-operation in activities that are aimed at task execution and production. Along with orientation towards the goal goes to the need to meet the social-emotional ties and needs of members. These are, among other things, the need for affiliation, achievement, self-confirmation making. Social relations are linked to the goal of work, but they can develop and maintain after working time. These small working groups are formal groups with certain and established obligations and defined rights of members. They always have a formal leader who has a certain mo- and rights to other workers. Standards are relate exclusively to the task of the group and relate to how and how much to work and at what pace. Integrated systems from multiple workgroups organization.

By conducting an organization with a psychological, as well as other approaches, it is necessary to guide the case that the organization consists of working groups and that the members of the organization always and members of smaller working groups. As small group relationships depend on the characteristics organization, and the characteristics of the organization as a whole depend on the situation and the atmosphere in small groups (Rot, 1982). Organization of companies today is no longer pyramidal, vertical, ve? is horizontal and "flattened". Until now, organizations are, in particular, big enterprises, had a "narrower range of control" and "deeper organizational pyramid", by contrast of the latest trends favored by computerization of companies and organizations all "fold" and with a wider range of controls. The organization is transformed from that vertical in horizontal. In the horizontal organization there is no class hierarchy, knows? there are expert teams for specific jobs (Sikavica and Novak, 1999).

In such circumstances, the working group model becomes overwhelming and inadequate requires switching from group model to team work model. The reason for moving to a new one model is not operational developmental, creative nature. Transforming a group into a team It is part of the process of learning in organizations and, more appropriately, the result of organizational development (according to Storge, 2002). While working groups are clearly defined obligations and defined roles of members from the "top", with teams already larger emphasizes the individual characteristics of the members and their creativity. Real the team would be a jazz orchestra. Everyone improves creatively on their instrument, but the whole thing sounds harmoniously. The enjoyment of such a play (or work in the top team) starts from finds self-control rather than "command" coming from a conductor or someone outside team.

There are many benefits of introducing teams to organizations. Teams can make it easier expanding the company and enabling faster information flow, leading to an increase flexibility (Mohrman, Choen and Mohrman, 1995; Yancey, 1998). That's it is achieved through the increase of communication and through the involvement of employees in making decision. Horizontal communication is increased relative to the vertical. Also, productivity gains, job absenteeism, and increase are reduced quality of service, safety and employee satisfaction (Yency, 1998).

Guzzo (1986, according to Yancey, 1998) defines the team as a group of individuals to be seen they are seen from the environment as a social entity, who are excited about the work they are doing as members of the group. They are included in the larger social system and perform tasks that affecting others, within and beyond that social system. The key is to be independent and this differentiates them from workgroups. Team members are many times over members of the group. The ability of a team's staff is intense and constantly evolving, and he has them opportunity to show and prove. The working group is denying it because of the clearly defined roles and small opportunities to change in a predefined structure. This results so that team members recognize their share in the team result while the team member is working I can mostly see only what I'm doing. Also, in teams it is, unlike working groups, the role of leader is reduced to the minimum. Executives and managers cease be separated by a hierarchical gap between the worker and the knowledge of the manager complement the knowledge of specialists and referents (Tudor \& Sri, 1998). Basically every one, team is a working group, and the working group becomes the team when it is organized so successfully fulfills the purpose of existence. So this is a better edition of a working group. When your group work with the necessary features - identifying members with purpose, comfortable working motivation, motivation, creativity, participation in leadership jobs, etc. - becomes a team. 
Most of the managers in a good team look like the paddles in the eighth. To accomplish goal, everyone must be "as one". No one should chew myself or lower, faster or slower than others not to endanger the overall success. Oscar is perhaps a good metaphor for a group of people who does some well-planned job, but in the team members are different mutually complement. Instead of a homogeneity similar to that, that government a difference that enables flexibility and heterogeneity, but also a quality performance joint work. They are more like a racket that will win if everyone is well-off but not all of them must do the same. The team is being watched by individuals who possess three basic groups of knowledge and skills. The first are technical (functional) knowledge which are based on education and profession. It is desirable to team different individuals a profession that can act interdisciplinary and so every common problem to look at is to handle a variety of different angles. The following are the problem solving skills and making decisions and social skills (listening, verbal and nonverbal speech, assertiveness, conflict resolution and the like) (Tudor and Sri Lanka 1998). Teamwork, therefore, represents a form of coordinated activity performed by a deliberately organized group people so the division of labor is based on immediate cooperation and competence different experts, and not in their position in the formal hierarchy (according to Petz, 1992).

We differentiate between two types of teams: an administrative and an entrepreneurial team. Administrative the team is also called bureaucratic and represents a transition from the working group to the team. It's here formal selection of members still exists, authoritarian leadership, non-respectable organizational rules and distribution of jobs by specialized units, but the team open to innovations and gives its members, albeit cautiously, the ability to develop and of learning. The entrepreneurial team aims to develop, members of the problem approach the research and creative, leadership is a liberal and democratic, multi - disciplinary discipline in member organizations, organizational rules are flexible and dynamic, the team is open for the environment and innovation. However, to make the team enterprising, with all this the systematic work of the manager and his associates, members, is required to establish a quality foundation for joint work. Team Building Requires systematic approach in all team development periods: from the concept through decision to the next the first team meeting. Each of the procedures that will take place at the earliest stage later - Irrevocably, positively or negatively, affect the overall work of the team. If it is from the start does not lead to the knowledge required by the team, its size, representation and balance of team and private roles of individuals, differences in team, the desirable characteristics of the membership of the members, their appropriate inclusion in the team tasks, structuring team roles, decreasing the ability to achieve an effective, efficient and pleasant team - efficient team (Tudor \& Sri, 1998).

\subsection{Factors Affecting Teamwork Efficiency}

Organizations are constantly looking for ways to help them compete with the competition complex in new ways of working. Increased dynamics in economic and social Sociological circles have influenced many organizations to analyze work strategies as well there are new ways of improving the quality of work (Ingram et al., 1997). Never before in the history of the work process The team work model was no longer important for functioning successful organizations like today. Research results show that the introduction of teams the organizational structure leads to an increase in efficiency and quality of work (Applebaum and Batt, 1994; Macy and Izumi, 1993; Levine and D 'Andreas-Tyson, 1990; according to West et al., 1998). Hence, there is a great deal of interest in identifying factors that Impact on teamwork efficiency.

What do we mean by the term efficiency? In Business Solution Efficiency is a strategic concept related to the research of profitable potentials in organization. Hofer and Schendal (1986, according to Ingram, 1997) argue that efficiency is important because it represents the determinant of organizational success and refers to satisfaction organizational environment. They start from the fact that efficiency is the degree of connectivity between actual and desired results. Drucker (1974, according to Ingram, 1997) defines efficiency as "the degree to which the desired result is achieved". Blake and Mouton (1964, according to Ingram, 1997) emphasize that organizational efficiency is most prominent when Management at the same time succeeds in orienting both production and people.

There is no single measure to determine the effectiveness of teamwork. According to a model suggested by Schermerhorn (1995, according to Ingram, 1997) can be measured through individual and group results that are the product of the process of formation and internal processes in groups that lead to results. The process of forming the most are influenced by teambuilding managers, while in-house processes one of the most influential determinants of greater timely efficiency. They belong to them orientation to the common goal, cohesion, communication, decision-making, work tasks and conflict resolution. According to Hackman (1987) and Sundstrom (1990, cf Guzzo and Dickson, 1996) Efficiency can be traced through: team results (qualitative or quantitative, speed, customer satisfaction, etc.), through the influence of the group on 
it or through the ability to make progress in the team's efficiency in the future. A similar definition and Guzzo et al. (1993), which puts a special emphasis on the motivational factor which called the potency, but more about it later.

Sundstorm (1990, according to Draft, 2000) emphasizes the effectiveness of teamwork based on the ultimate result of the work and satisfaction of the team members. The end result is determined through a qualitative and quantitative achievement team defined through teams goals. Satisfaction is based on the team's ability to meet the personal needs of the members and to increase the loyalty of the team. Factors such as types of teams, structure, composition, then homogeneity or team heterogeneity in with respect to age, gender, skills, knowledge and attitudes, influences on internal processes in teams that ultimately determine the satisfaction of the members and the end result.

Employee attitudes and customer perception of service quality have been shown significantly associated with profitability organizations (Schneider, 1990; Jonson, 1996, Rucc et al., 1998; according to Newman, 2001), and according to Campion, Mederser and Higgsu (1993, according to Yancey, 1998) Efficiency is defined in terms productivity, employee and client satisfaction, and manager ratings. According to this to authors of the nature of work, the perseverance of members, team composition, organizational context and the processes in the team are linked to the stated efficiency criteria. Teams should have a common goal that members only work together and combine knowledge with capabilities from different areas can be achieved. Each member will also have the opportunity to give your contribution to solving the problem. Feedback on common successes, or failures, knowledge of the common outcome and the rewarding system that evaluates the team, not the individuals in it, encourages motivation for common work, that's important.

The role has the support of their manager who provides feedback on the results work the whole team. He also encourages communication between teams and so on the development of a competitive spirit within them. Processes in teams such as conflict, developing group norms, cohesion, and belief in the team's efficiency as well have a great impact on the team's efficiency (Yancey, 1998). In accordance with the criteria efficiency mentioned by Champion et al. (1993, according to Yancey, 1998) in this paper.

The criteria for testing the team's work efficiency were their manager's estimate financial performance indicators of teams, their self - assessment of efficiency and their customers satisfaction ratings service. In the introductory part, the review is on some of the most important factors influencing the effectiveness of teamwork, which are the size teams, team roles, team development stages, cohesiveness, team standards and potentials.

\section{The size of the team}

Since researching the characteristics of small groups in the organizational environment it was found that the group is most effective when it has 7 members. Teams have the most 3 to 20 members. Increasing the number of members reduces the possibility of interaction and with a mutual influence. We differentiate small teams (2-4) and big teams (12+). Small teams are more comfortable, members ask questions and exchange more experiences. In a little the team is more satisfied with the satisfaction of the members, before the relations are established.

Members are much more trying to be in good relationships, more difficult informal relationship and having minimum requirements for the manager. Misunderstanding and dissenting opinions arise will be in teams that have more than 12 members. A large number of members favor forming a subgroup and making conflicts easier. It is also characteristic of leaving the team and absenteeism. Poor communication and reduced access to work lead to low satisfaction of members (Draft, 2000). So, small teams from 4 to 12 people are optimum for a quality and efficient teamwork.

\section{The ranks of the team}

Many experts have been watching organizations trying to answer why some the teams succeed, and others fail. Studies in this area instruct you to teams work much more efficiently if the correct combination of team roles is present. "The role is a set of exemplary types of behavior attributed to someone who takes the days position in a social unit "(Robbins, 1992, p. 93) It is known that team members they should have adequate skills and ability to do the job. Besides, Torrington (1985, according to Prichard and Stanton, 1999) emphasizes that it is efficient team functioning requires the team to be equally oriented to the task as well as on social emotional behavior of members. There is a need for each team different team roles. A team of people who are different to each other, if they are affected to deal with such a mark, will always give better results than the team they are in all members likewise. The team certainly needs roles that care for the team task, but also the roles which cares about people. Belbin (Belbin 1981, according to Tudor and Sri, 1998) differs 8 team roles: creator, 
researcher, promoter, coordinator, evaluator, developer, builder and builder of the team. A compelling sum of all team roles is provided by an ideal team, ie a team that It really does have great prospects for success. Everyone hides more traits and tendencies, me where two or three prevail. That is why the composition of only four can be cover all eight roles. Each member, in accordance with their own characteristics and preferences, will be taken in such a case and in several roles (Tudor and Sri, 1998). Although best known, Belbin's questionnaire for established roles in the team is unsuccessful psychometric validity. Also, it is not a fully certified model by which

Efficiency depends on the proper timing of these 8 team roles (West et al., 1998).

In addition to the combination of various roles, Guzzo (1996) states that team work efficiency is high positively influences and heterogeneity with respect to the line of personality, sex, attitudes, and attitudes previous experience.

However, these differences also threaten the problems. People are by their nature is closer to those who are similar to them, rather they co-operate with the same people. How to code teams are valid for the versatility of members, interdisciplinary and diverse, it is big the likelihood of subgroup emergence and misunderstandings and conflicts appear (Tudor et al Sri, 1998). It is therefore important to conclude that efficient teams must have people oriented, as well as those with social-emotional roles. With proper the balance of these types of role team will be successful, and the team members happy (Draft, 2000).

\section{Team development stages}

Team development is a dynamic process. Most teams are in constant state change. To make the team as efficient as possible, it must first become a team. Still in 1970 Tuckman is identified the 4 stages through which the team must work to be successful. These are the formation, orientation, growth and the final stage in which the team is developed. Each stage is the same worthwhile, as part of the planned path to team maturity, and only the one in which it is bad is bad the team develops insufficiently or holds too long (Tudor and Sri, 1998).

The first stage of team development is formation. Members are also introduced to each other they are trying to get close, but also for the right place in the group structure, while they are the leader try to present and explain team goals and try to determine individual work roles in the team. Group cohesion is just in the making. The comrades have determined that the interlocutors in the first team period listen to each other very superficially are lacking in interest in the moods and inner states of their colleagues. Therefore the team it works scattered. The joint work of specialists of various professions has not yet begun.

Different knowledge does not intertwine and no new com- munity is created. Work is not yet effective, and internal team relations are underdeveloped.

The second stage is orientation. After gathering, dating and dating on work together, the group of individuals begins to gradually take on the team's features. Group it is more efficient to work and invest more in yourself. At this stage of the majority trying to engage in joint activities, more care for associates, and so on group connectivity. But most people still feel that the results are severely and slowly.

The first semi-rigging gun appears due to inefficiency. As a result, it will be reported

mood swings, frustration and helplessness. Negative reactions can also occur - members of the manager and colleagues. The final group completes the second stage of formation internal hierarchy. Find out who's in the group. Tim enters his second phase with more ambition. Only when the head and members simply decide to consider theirs of the current methods of work and to improve them, a crucial second phase of the team begins work.

The third stage is growing. After a successfully overdue period of working crisis had to lose due to the lack of expected results, by forming a hierarchy, the team is happy and in a harmonious whole. Communication is much more effective and there is a strong cooperation to the members. The team's standards are high, high connectivity and growing use a number of different new skills and methods of work. The working group is undergoing its third phase (normative), trying to complete "agreements" about the roles they belong to, o status, norms of behavior. Team Building Begins When Creating Communication And constructive criticisms are primarily given meaning in team atmosphere. Word is about a period in which the methods of teamwork are improved, but also different characteristics 
The fourth stage is the stage of a team developed. Common goals become the most important ones the goals of each thread. The moral team is very high, the members are satisfied, they turn to work because their interrelationships stabilized in the right way. Everyone fills its team role, the individual debts are well-integrated into the team,the work of everyone with each one is harmonized, the whole team is facing a common business goal, The members express themselves with confidence, they are all aware of team strength, everyone is satisfied because his work in the team provides a multitude of ways and opportunities for satisfying both personal and collective need. At this stage, the team is highly efficient with minimum and discrete support Leader (Tudor \& Sri, 1998).

These stages describe the processes in the development of each small group and, although highly criticized,the Tuckman model depicted until today (Rot, 1983).

\section{Cohesiveness}

Cohesiveness Team cohesion is defined as the cohesiveness of each group so it represents "the complex dimension of the group expressed as the attractiveness of the group of members and their mutual attraction, group connectivity, and disengagement resistance, loyalty and affection of members of the group, goals and ideals of the group "(Petz, 1992).

Cohesion of some authors such as Newcomb (1965) or Cartwright (1968, according to Rot, 1983) they also give an important and central place in explaining the functioning of the group. They emphasize that cohesion is the result of the action of numerous factors and represents The basis for many phenomena important for the functioning of the group. Cartwright (1968) (according to Rot, 1983) distinguishes 4 groups of conditions that are justified to be considered sources cohesiveness. These are

(1) motives, ie the motivational basis of the group member;

(2) characteristics Groups such as group goals, action, reputation, and others;

(3) expectations of members and estimates that this expectation is realized;

(4) comparing satisfaction and the benefits that can be gained in the assessment group can benefit from membership in others identical groups. Coach team will regularly be consistent with the way it is experienced by its members. If they are attracted to team work and people in it whether they feel attached to the group and its goals, and if they are experiencing group "with your", the degree of cohesion will be high. If people are in the mood Conversely, we say that cohesion is low and as such disrupts the team's actions and can lead to its collapse (Tudor and Sri, 1998).

The result of team cohesion we can look through morale and team efficiency. It is known that morality is already in highly cohesive teams due to increased communication among members, friendly climate in the team, loyalty to the team and the participation of members in decision making and activities. Hence, high cohesiveness positively affects pleasure and morality team member. As far as efficiency is concerned, research results show that it is cohesive Teams have the potential to be more productive, but the degree of effectiveness depends on more

factor (Draft, 2000). In Seashore research (1954, according to Rot, 1982) has been established is that the efficiency of some cohesive groups was significantly less than efficiency nonkoheziv. The explanation finds that in cohesive groups efficiency depend on the standard agreed upon by the members of the group. They can adopt eitherHigh or Low Efficiency Standards and Depends on High or Low Efficiency.The latest finds in Mullen and Copper (1994, by, West and sur., 1998) point toa significant link between team efficiency and cohesion and that direction of influence is good when it comes fromwe conclude on the results of cohesion but when it comes from cohesionwe conclude the efficiency. Therefore, cohesion does not necessarily lead to greater efficiencythe team, and to bring it, it is necessary to monitor and work on itorientation (Tudor \& Sri, 1998).

\section{Conflict}

According to Robbins (1974), conflict is antagonistic interaction in which one the stranger tries to block the intentions or goals of the other. Competition for team members, according to some authors, it can have a healthy effect because it gives the energy to the members for to achieve better results. Conflicts within the team can improve decision-making because leading to multiple opinions. Research shows that the level is low conflicts with top management teams associated with bad decisions. Likewise too the conflict is destructive, destroys relationships and interferes with the exchange of information and ideas (Koehler, 1984). According to the Draft (1992) there are several factors that lead to conflict: 
limitation of material for work, undefined team role and work tasks, noise in communication, interpersonal disagreement, differences in power and status of members, and other goals set (according to Draft, 2000). We are watching conflicts from the point of view their impact on team success, we share them with constructive and destructive ones helping work and those who move away from the work and life of the team. Like you already? conflict, conflict helping to see problems from all sides, to explore all the possibilities solutions and eventually apply it better. After a positive solution, one sometimes feels an increase in mutual understanding and openness among the members. They're fixed relationships with us, growing trust and team cohesion. The end result of the positive conflict solutions are to increase team creativity, enhance organizational stability, faster fixing and problem solving, encouraging change instead of stagnation and profiling the identity of a group and an individual. Negative influences of conflict will still be about? more obvious. The appearance of negative emotions - anger, aggression, non-operability, absurdity, dissatisfaction - and overcoming them in team atmosphere soon block any successful action. Characteristic is the rapid decline of group and individual motives, weakening of inner connection, disabling effective communication, lack of willingness to cooperate, animosity growth, dissatisfaction.

Since every conflict arises under special circumstances and on a regular basis reflects the peculiar situation in which the team at a particular time found, even two we must not solve the simplest conflicts by the same pattern and by equal means (Tudor \& Sri, 1998). Draft (2000) suggests several techniques for resolving conflicts

I'm in people in teams and in teams. The first is setting up a superior goal There are some other important factors influencing the effectiveness of teamwork As the last feature of a team that influences its efficiency, we are announcing it the aspect of motivation quoted by Guzzo et al. (1993) in recent group theories efficiency, which is of key importance for understanding the design of this research.

Many of the experts were concerned with the study of human motivation. But no theory did not give a simple answer to the question of how to motivate a team (Tudor and Sri, 1998). Recently, more research into motivation in the group approaches more theoretically rather than empirically. Guzzo et al. (1993, according to Guzzo and Dickson, 1996) introduce the concept of the potency of a group that represents a common belief in efficiency team. The power structure represents, unique, measurable and significant (practical and theoretically), a psychosocial phenomenon that is not contained in existing motivational group-related models. They state the power of this motivational conviction may be a significant predictor of efficiency (Sayies, 1958; Hackman, 1990; Larson et al LaFasto, 1989; according to Guzzo et al., 1993) in service activities and others area? them. Guzzo (1993) defines efficiency as measurable results of group work, the influence the group has on its members and the opportunities that the group has to do well in the future. He cites the potential of the group as one of the most important efficiencies team. Potency is a belief group that can be efficient and describes it through the conviction of members to be able to cope with their abilities (Guzzo et al., 1993). Potential influences feedback on team work results, indoor and outdoor external group factors. The feedback on performance results refers to the criteria evaluation of the workflow (managers' ratings, customer satisfaction, satisfaction other members of the organization working with the team). Internal group factors are linked for knowledge, skills and abilities of members, size groups, fatigue and stress. External factors include the available work material, linking the team's goals with the goal of organization, the influence of the manager and the reputation that the team has in the organization. Guzzo and Champbell (1990, according to Guzzo et al., 1996) indicate that those groups exhibit strong sense of potential their groups are more difficult and more efficient. If teams receive feedback about the results of the joint work and the control of internal and external group factors, levels Team Team Potential can be a good predictor of Teamwork Efficiency (Guzzo i sur., 1993).

\section{OBJECT OF THE INVESTIGATION}

The growth of organization and the increasing complexity of the organizational structure occursthere is a need to introduce teams in which people work together to achievethe common goal of the organization. There are many reasons for this. One has established connectivitybetween teamwork and the overall performance of the organization. So, changes in efficiencyteams have consequences and changes to a much larger system because when they grow upteam efficiency, increase efficiency and the entire organizational system. Therefore inContemporary organizations see the increased efforts of the executives in creationcompetent teams, necessary for developing new business solutions, motivating motivationpeople for the desired work environments and increasing the efficiency of work in general. Accordingly, The purpose of this research was to contribute to the understanding of team work phenomenaefficiency, factors that influence it and check some of its measurement methods. 


\section{PROBLEM OF RESEARCH}

Investigate the differences in work efficiency - four compliant team of Privredna banka u Kosova, based on self-assessment of the team's efficiency and performance measures.

\section{HYPOTHESES}

Before the survey, at the request of the author, senior team manager rated it each team according to the objective financial measures of the workplace. Criteria for assessment The efficiency of the teams was the benefit the Bank has of the contracts that have been concluded by each individual team. It should be emphasized that it has only been taken as an efficiency measure the value of the individual contracts and the number of clients with whom contracts have been concluded. The analysis The senior team manager ranked the teams and gave a qualitative description each team with respect to business results. The ranking of teams is shown in Table 1.

Table 1.- Rank the ranking of teams according to the senior manager score

\begin{tabular}{|l|l|}
\hline Rank & Tim \\
\hline 1 & A \\
\hline 2 & B \\
\hline 3 & C \\
\hline 4 & D \\
\hline
\end{tabular}

These senior team assessments were taken as the basis for the posting the following hypothesis:

Teams are differentiated by self-assessments of work efficiency and estimates of their customers about service satisfaction. The results of earlier research have shown that there is a high correlation between attitudes of employees and their clients (Bowen, Schneider, 1988, 1980, 1985, according to Adist et al., 1996) and is expected to: There is compliance in selfassessment of the work efficiency of team members and satisfaction ratings of their clients' service.

\section{METHODOLOGY}

\subsection{Respondents}

Two groups of respondents participated in this study. The first group employees of the Business Services Department of Privredna banka * in Zagreb and the other their clients are grouped.

There are 16 people in the Department of Business Administration who are deployed in four generations team. In each team there are two client relationship managers, one credit an analyst and a person in charge of credit administration. Relation Managers clients contact customers and, depending on their requirements, offer products Bank. They formulate a loan proposal that along with the required Documentation on the business of a legal person (enterprise) analyzes credit analysts ar Once it is determined whether the legal entity is creditworthy, the loan is granted or granted the request refuses. If the loan is approved, the person from the credit administration is preparing final, administrative part of the job related to the submission of reports, preparation of contracts etc.

This job in three stages before the team was introduced was performed by one person, most likely client relationship manager and senior managers decide to restructure this sector by introducing team work. Each team should be covered by an expert knowledge for these three levels of work. The City of Prizren is then divided into four parts and it is each team got its part of the city that it covers. This distribution was made to be made it easier for managers to choose clients and to make clearer differences me in teams. All four teams are formed by the same criteria, they have the same individual goals, work in equal conditions, and work experience are valued at the same way. It can be said that members are in line with some basic characteristics (age, sex, education). In this research team we named teams A, B, C and D.

Literature often states that customer satisfaction with the service can be good the predictor of the success of the service activity and as a measure of the work of everybody Each team took their customers' assessment of service satisfaction. 
Clients in This research was the people who represent companies and are in contact with to your team's representatives. The condition for completing the questionnaire was to make a person longer

\subsection{Instruments}

\section{Teamwork Efficiency Questionnaire}

To measure self-assessment of team work efficiency, the Questionnaire was used to analyze the efficiency of team work. This questionnaire was compiled by Bateman, Wilson and Bingham (2002) to determine the needs of teams working in service activities.

The questionnaire in the original version consists of six categories of questions related to the team teams evaluated by team members. The results show the efficiency of each category as well can be used to improve teamwork as well as to compare teams.

The categories in the questionnaire are:

1. Team synergy - sense of belonging shared by team members.

2. A common goal - the existence of clearly defined goals set team and whose execution is constantly monitored.

Skills - training of team members, competence in performing their own part of the job and flexibility within the workplace.

Use of working material - all work materials, including buildings and equipment, are used to maximize the power of the plug.

5. Innovations - Finding ways to improve productivity and ways work.

6. Quality - degree of familiarity with client needs and standards listening to their satisfaction.

The authors of the questionnaire indicate that when analyzing the internal consistency of the questionnaires reliability ranges from 0.97 to 0.98 . Cronbach's alpha coefficient for all estates of the questionnaire is 0.98 , which indicates a high internal consistency of response respondents. The sample consisted of 400 participants deployed in 37 teams. All these teams working in service activities related to health care and social care in the Down Lisburn $\mathrm{H} \&$ SS Trust from Lisburn (UK) and consists of members of various vocabulary (from managers, psychologists, therapists, senior managers, information staff, staff companies, etc.). The research involved only teams that are at least six months old.

Prior to the research itself, a pilot - research was carried out on a group of managers and staff working in the company. Evaluation of pilot studies has shown that it is necessary clearer and more specific use of some terms to ensure the applicability of this questionnaires for teams working in different working conditions.

In this paper, the categories are combined with the common goal and the use of working materials because it was estimated that given the nature of the work carried out by the members of the examination teams of these categories would not be discriminatory. Questions from other categories were translated with the expert translator (APPENDIX 1). In the final version, the questionnaire is questioned consisted of 32 questions, 8 questions in each of the categories. The questionnaire consists of a scale Likert type responses and subjects on scales 1 to 5 indicate the degree concordance or disagreement with a particular statement (1 - I strongly disagree, 5 - very explicit

I agree). Claims in the questionnaire were formulated so that the team evaluated the efficiency your team, not personal efficiency. On a sample of 16 respondents of respondents in 4 teamsReliability by Question Categories, expressed as Crombach's Inner Coefficientconsistency, ranging from 0.77 to 0.87 , and for all questionnaires, $=0.876$.

\section{Customer satisfaction survey service}

The customer satisfaction survey questionnaire was drawn up on the basis of the analysisjobs are team members for all three levels of work and in accordance with the categoriesTeamwork Teamwork Questionnaire. The questionnaire consists of 16 questions put togetheraccording to predefined categories. The categories are: communication, skills,trust and quality. These categories in the literature are some of the criteria forevaluation of service quality (Peter and Donnelly, 1991, 
according to Churchill, 1995). And inthis questionnaire of the response scale is Likert's type and the respondents give grade estimatesstacking with a single statement on a scale of 1 to 5 (from 1 - I strongly disagree with 5 - I strongly agree). Crombah coefficient of internal consistency by categoriesThe questionnaire applied to 83 clients ranges from 0.511 to 0.776 and for allQuestionnaire amounts? $=0.884$.

\subsection{Procedureln}

September 2002, the Management Board of the Privredna banka in Kosova approved the authorshipconducting research in the Business Services Department. The research was conducted inOctober 2002. Team members are divided into questionnaires at the beginning of the worktime and are asked to pause them. The instructions pointed out that it was a testanonymously and you only need to write the name of the team to which they belong. Also, it has been emphasized that the estimates relate to the efficiency of the team they belong to, and not totheir personal efficiency.Client statements were collected at the client reception office. After meeting withWith his manager, the client was asked to fill out the questionnaire in the waiting room. INthe note emphasized that the satisfaction of the Service in the Department of Labor was assessedenterprise has. Clients filled out the questionnaire anonymously and were just supposed to writewho are contacted by a person in the Business Services Department

\section{RESULTS AND DISCONTINUES}

\subsection{Examining Teamwork Efficiency}

Within the context of the problem we are concerned, what kind of relationship is between us to work efficiency teams based on self-assessment of efficiency and measures of the workmanship.

First of all, we have to look at the team's estimates given by their senior manager, which were used as a basis for the research hypothesis of this paper. From Table 1. it can be seen that the most efficient team on the score of senior manager team B is the second place occupied Team A, Team 3, while Team D is the worst team. How is Team Senior Team evaluated the teams differently according to the quantitative criteria of the job, interesting whether the teams are different from self-assessments of efficiency. The results that were obtained using the Teamwork Efficiency Questionnaire are presented in Arithmetic mean estimates and standard deviations for results inTeam Team Efficiency Questionnaire for 4 Teams

Table 2 and Figure 1.

\begin{tabular}{|l|l|l|l|}
\hline & N & M & SD \\
\hline Team A & 4 & 3.096 & 0.287 \\
\hline Team B & 4 & 3.703 & 0.774 \\
\hline Team C & 4 & 3.352 & 0.454 \\
\hline Team D & 4 & 3.984 & 0.538 \\
\hline
\end{tabular}

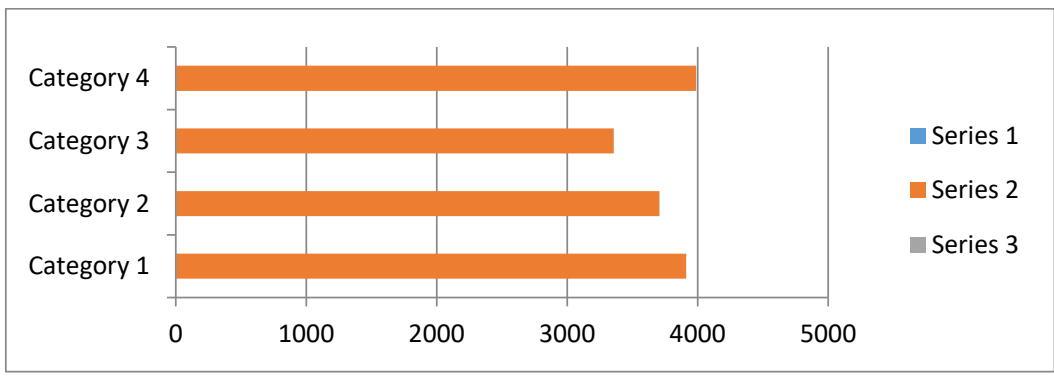

The overall score for each team is shown as the arithmetic mean of the estimate of a particular team. The results are also presented graphically for easier reading of the relationship between the mouse teams.

Table 2 - Arithmetic mean estimates and standard deviations for results in 
Team Team Efficiency Questionnaire for 4 Teams

\begin{tabular}{|l|l:l|}
\hline Rang & Tim & Average sumrankings \\
\hdashline 1 & D & 10.50 \\
\hline 2 & A & 9.50 \\
\hline 3 & B & 9.25 \\
\hdashline 4 & C & 4.75 \\
\hline
\end{tabular}

Due to the small number of groups and the small number of respondents in the groups $(\mathrm{N}=4)$, forDetermining differences between teams was inappropriate to use the Variant Analysis thatis most likely to be used when analyzing relationships between groups. In cases where it is like thissmall $\mathrm{N}$, it is recommended to use nonparametric tests. Adequate replacement forThe analysis of variance in nonparametric statistics is the Kruskal-Wallis test.By testing the significance of the difference in the rank of rank, it has been determined that the teams are statisticallydo not differ significantly in the overall result in the questionnaire $(? 2=3.473 . \mathrm{df}=3, \mathrm{p}>0.05)$.

As can be seen from Table 2, Figure 1 and Table 3 of the teams' order according to self-assessments of efficiency differ from the ranking of their superior managers. According to the manager's assessment Team B is most effective while Team $D$ is rated as worst. According to self-assessments of teams it is apparent that Team $D$ is evaluated as most efficient, while Team $B$ is only three times self-assessed. Different direction of the manager's rating and self-assessment of efficiency can be attributed to the different aspects that were taken as efficiency measure. A Senior Quality Manager is based only on objective quantitative team performance results, while team members evaluated the effectiveness of the teams related to the characteristics of team work.

There is no difference between the teams in the overall result of the Efficiency Questionnaire Teamwork can be explained through the same aspect of motivation as a team member Guzzo (1993) calls the potency. Champion and associates state that the potency group belief that it can be efficient (according to Yancey, 1998). From the results in the Table 3 . It is obvious that the average estimates range from 3.35 to 3.98 on a scale of 1-5, which is shows that members of all teams of teams evaluate their teams as overlapping efficient in all examined aspects. The authors state that the potency is influenced management support, knowledge of past achievements of the team (feedback on results of work), perceptions of members of the knowledge and skills of colleagues. How is it the introduction of teams in this Service has led to many positive changes the Bank's management even closer to the employees themselves, the assumption is that they are the teams had their support. Also, this survey was conducted in October, and The annual report on the work of teams is at the end of the year, so the teams are not they had insight into the final business results and the work of their team was evaluated on the basis subjective business estimates. How Power Is Influenced by Knowledge of the Past achievements can make the results different than the survey was made after reviewing the team's results in the results. Furthermore, all four teams were formed by highly qualified people who have a long-standing experience in working with credit so it is the assumption that the members of the team are perceived to be competent, that is high value the knowledge and skills of other team members.

Continuous work on education and development existing teams are greatly influenced byincreasing their efficiency. That is why it is important to recognize the area to which it ismore emphasis needs to be placed on team development. Results displayed byquestionnaires (synergy, skills, innovation, and quality) give insight intofunctioning of the teams by the mentioned categories and enable interventions onareas are key to improving organizational efficiency. The results are shown in table 4.

\begin{tabular}{|l|l|l|l|l|}
\hline & SYNERGY & SKILLS & INNOVATION & QUALITY \\
\hline $\mathrm{M}$ & 3.945 & 3.555 & 3.7266 & 3.719 \\
\hline $\mathrm{SD}$ & 0.593 & 0.584 & 0.614 & 0.756 \\
\hline
\end{tabular}

Wilcoxon's test of equivalent pairs tested mixed differencesEstimates by $N=16$ Classes of Teamwork Efficiency Questionnaire, and nota statistically significant difference between the estimates of team members by categories was foundquestionnaire. This shows that employees of the Service Department work with companies that work in thesethe teams evaluate all four categories of questionnaires equally. How mediocrethe estimates for each of the overproduction 
categories (as can be seen in Table 4)it can be said that team members highly evaluate the efficiency for each of the categoriesTeamwork Teamwork Questionnaire.Further, we were interested in how the relationship between teams was by categoryquestionnaire. Results of basic statistical parameters for each team by categoryof the questionnaires are presented in Table 5 and in Figure 2.

\begin{tabular}{|l|l|l|l|l|l|l|l|l|l|}
\hline \multicolumn{3}{|l|}{ Category } & \multicolumn{2}{l|}{ SYNERGY } & \multicolumn{2}{l|}{ SKILLS } & \multicolumn{2}{l|}{ INNOVATION } & \multicolumn{2}{l|}{ QUALITY } \\
\hline Team & N & M & SD & M & SD & M & SD & M & SD \\
\hline A & 4 & 4.063 & 0.564 & 3.969 & 0.157 & 3.781 & 0.373 & 3.813 & 0.297 \\
\hline B & 4 & 4.094 & 0.695 & 3.344 & 0.976 & 3.719 & 0.695 & 3.656 & 0.780 \\
\hline C & 4 & 3.656. & 0.563 & 3.156 & 0.329 & 3.469 & 0.695 & 3.125 & 0.974 \\
\hline D & 4 & 3.696 &. .695 & 4.750 & 0.270 & 3.938 & 0.793 & 4.281 & 0.524 \\
\hline
\end{tabular}

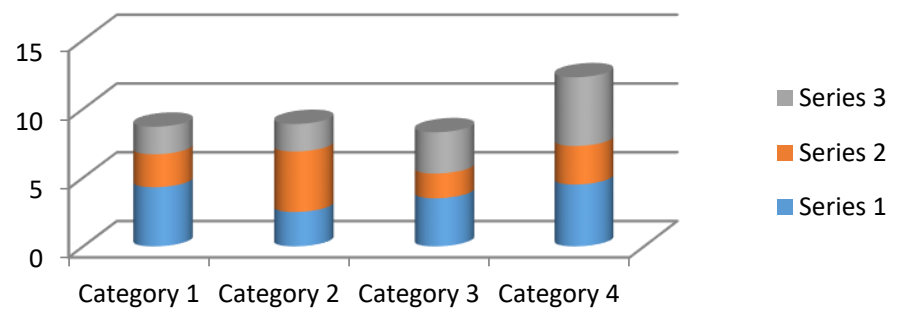

View self-assessment of Teamwork Efficiency for Four Teams byquestion categories

Hence, these results show that the teams do not differ statistically by category of questionnaire, but from the results presented in Tables 5 and 6 and in Figure 2. we see that Team $C$ in all question categories had the lowest score. If it does Let's look at both Figure 1 and Table 2. We can see that according to the overall result the team has lowest result by selfassessments. How is the statistical analysis of the obtained results?

\begin{tabular}{|c|c|c|c|c|c|}
\hline CATEGORY & TEAM & $\begin{array}{l}\text { Average } \\
\text { sum } \\
\text { rankings }\end{array}$ & $X^{2}$ & $\mathrm{df}$ & $p$ \\
\hline SINERGY & $\begin{array}{l}B \\
A \\
D \\
C\end{array}$ & $\begin{array}{l}10.38 \\
9.13 \\
8.75 \\
5.75 \\
\end{array}$ & 2.062 & 3 & 0.560 \\
\hline SKILLS & $\begin{array}{l}\text { A } \\
D \\
B \\
C\end{array}$ & $\begin{array}{l}12 \\
9.63 \\
8.25 \\
4.13\end{array}$ & 5.843 & 3 & 0.120 \\
\hline INNOVATION & $\begin{array}{l}\text { D } \\
B \\
A \\
C\end{array}$ & $\begin{array}{l}11.13 \\
8.75 \\
8 \\
6.13\end{array}$ & 2.300 & 3 & 0.512 \\
\hline QUALITY & $\begin{array}{l}D \\
A \\
B \\
C\end{array}$ & $\begin{array}{l}12.5 \\
8.38 \\
7.75 \\
5.38\end{array}$ & 4.669 & 3 & 0.189 \\
\hline
\end{tabular}

It showed that teams can not be distinguished, it is not justified to make conclusions about it that Team $C$ is the worst of these teams, but we can see the trend of the results obtained which suggests that perhaps more attention could be paid to monitoring the work and processes in team $\mathrm{C}$. 
The results of this questionnaire can be used by team managers as valuable feedback from team members about processes in a team that is sometimes due to scale jobs are put in another plan. Also, using this questionnaire members of the team had an opportunity to analyze your current functioning and eventually identify the domain which should be done more.

\subsection{Customer Satisfaction Testing Service.}

As a measure of the efficiency of team work in this paper, the client 's estimate was takensatisfaction with the service they receive from a particular team and we were curious about where they wererelationship teams with regard to their clients' estimates. By simple analysisvariants tested differences in overall client evaluation score and were not foundstatistically significant difference between teams according to client estimates $(F=2.424, \mathrm{df}=3 / 79, p>0.05)$. Table 7 and Figure 3 show the results obtained. Table 7. - Overview of basic statistical customer evaluation parameters on the Questionnaire

\begin{tabular}{|c|c|c|c|}
\hline & $\mathrm{N}$ & $\mathrm{M}$ & SD \\
\hline TEAM $\mathrm{A}$ & & 4.312 & 0.394 \\
\hline TEAM $\mathrm{B}$ & 23 & 3.991 & 0.589 \\
\hline TEAM $\mathrm{C}$ & 17 & 3.094 & 0.627 \\
\hline TEAM $\mathrm{D}$ & 24 & 4.198 & 0.967 \\
\hline
\end{tabular}

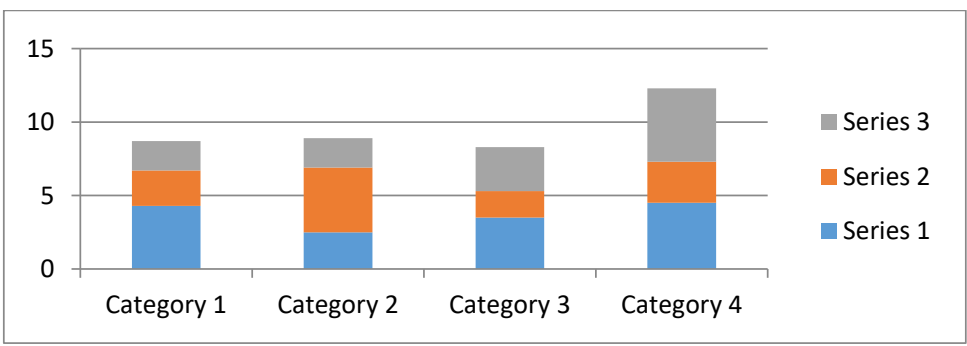

Thus, statistical analysis of results has shown that teams do not differ statistically notably by self-assessments, but not by customer reviews. However, they are analyzing graphs (Figure 1, Figure 3) and Tables 2 and 7 can be seen in this the questionnaire team $C$ has the worst result, team $A$ and team $D$ have high scores while team $B$ takes the third place. Though Team $A$ has a self-assessment score of 0.08 lower than the team's score $D$, while at client estimate $A$ has the highest score, there is a similar trend the relationship between team results. This trend of results is consistent with the findings in where the same is true of the perception of employees coincides with the real perception of quality of service by their clients (Newman, 2001). In research related to banking services it was established that there is a high correlation between employee attitudes and their clients (Bowen,

Schneider, 1988, 1980, 1985; according to Adist et al., 1996). From Table 7 it is seen that the service satisfaction estimates ranged from 3.094 to 4.312 (on a scale of 1 to 5 ) which shows that clients are generally satisfied with the service. How are the members of the team Assessing your team's work very efficiently, we can conclude that they are in this case Employee attitudes are consistent with the perception of their clients' services. It signals it the conclusion that team clients in the Sector of Business recognize the efforts of team members for by providing quality services.

Results displayed by categories of Service Satisfaction Quiz (skills, communication, trust, and quality) provide an insight into what aspects of the service you are providing are received from a particular team, clients are more or less satisfied with the Service enterprise has. They are shown in Table 8.

\begin{tabular}{|l|l|l|l|l|l|l|l|l|l|}
\hline \multicolumn{2}{|l|}{ CATEGORY SKILLS } & \multicolumn{2}{l|}{ COMUNICATION } & \multicolumn{2}{l|}{ CREDENCE } & \multicolumn{2}{l|}{ QUALITY } \\
\hline TEAM & $\mathrm{N}$ & $\mathrm{N}$ & $\mathrm{SD}$ & $\mathrm{M}$ & $\mathrm{SD}$ & $\mathrm{M}$ & $\mathrm{SD}$ & $\mathrm{M}$ & $\mathrm{SD}$ \\
\hline $\mathrm{A}$ & 19 & 4.445 & 0.445 & 4.513 & 0.460 & 3.961 & 0.522 & 4.329 & 0.486 \\
\hline
\end{tabular}




\begin{tabular}{|l|l|l|l|l|l|l|l|l|l|}
\hline B & 23 & 4.010 & 0.759 & 4.152 & 0.730 & 3.761 & 0.596 & 4.044 & 0.660 \\
\hline C & 17 & 3.397 & 0.749 & 3.794 & 0.686 & 3.735 & 0.693 & 4.118 & 0.606 \\
\hline D & 24 & 4.260 & 0.597 & 4.322 & 0.583 & 3.896 & 0.466 & 4.313 & 0.613 \\
\hline TOT & 83 & 4.175 & 0.666 & 4.211 & 0.662 & 3.840 & 0.564 & 4.202 & 0.602 \\
\hline
\end{tabular}

\subsection{Final Considerations}

More and more, the importance of systematic analysis has become increasingly apparent lately trained and educated employees in the skills and knowledge needed to make the most effective the way it works. For this reason, many companies are introducing ongoing training that is meaningful they increase employee satisfaction, and thus their effectiveness. Training staff combined with corresponding changes in attitudes increases self-esteem company staff, increase their membership of the organization and improve their knowledge and skills skills. Likewise, it ensures the shared sharing of knowledge and experience, it helps the same level of professionalism and the achievement of a high level of organizational culture.

Also, in the organizations involved in monitoring service activities Customer Satisfaction is a great way to determine the quality of the service you are doing the organization provides in relation to its clients' expectations. That way they get information that can be used as a means to determine how to improve processes in the organization, as a means of motivating workers and as a means controls for performance evaluation.

The results of the questionnaires used in this research may be helpful in returning Information to managers about some of the most labor-efficient aspects are put in another plan, and the emphasis is placed on quantitative monitoring performance indicators. If we compare rankings of teams ranked, ranked by senior manager according to the quantitative criterion of work efficiency, we see that he is not in consistent with the results obtained by examining other aspects of operational efficiency. How is it efficiency defined in terms of productivity, satisfaction of workers and clients and rating of managers, it is recommended to follow all of these criteria in order to get what more complete picture of worker's work efficiency.

Finally, it is important to emphasize the importance of co-operation between managers and organizational psychologists in the identification of problems and factors that affect the efficiency of team work. For unlike class working groups, teams "require" work on ongoing education of members, the development of potential members, maximum use of the full range of their knowledge and skills, developing creativity and, ultimately, critical approach to teamwork and processes in him. Knowledge of organizational psychologists (theoretical and methodological) and possibilities managers to apply this knowledge are the best way to contribute to understanding the phenomenon of the team's mode of operation and thus improves the efficiency of the whole organisations.

\section{CRITERIA AFFECT THE IMPLEMENTED RESEARCH}

The limitations of this research arise from the characteristics of the questionnaires used customer satisfaction and the time period in which the survey was conducted.

The first limitation is related to the Customer Satisfaction Questionnaire that is the author the same formed and there are no data to compare the results obtained. How is it the questionnaire used for the first time in this research is re-applied to validate this questionnaire and examine its content, criterion and constructive validity. It is also necessary to combine the direction of the claim because it is all claims in the questionnaire positively directed, which leads to the respondents (clients) are more satisfying than in the case when questions are asked in the same way ratio - satisfaction / dissatisfaction.

The authors of Teamwork Efficiency Questionnaires constructed a questionnaire for purpose recognizing the needs of team members working in their organization and work on their improvement. The article in which the questionnaire is attached is not theoretical the model on which a questionnaire was prepared, so it was decided before applying the questionnaire in this to explore two categories of questionnaire (common goal and use of the job) material). These two categories were excluded because it was considered, based on work analysis places, it would be non-discriminatory, ie, that these four teams do not differ by that categories. After studying literature related to team effectiveness checks the work has shown that the results in these two categories are useful information in the analysis team work efficiency. In APPENDIX 2 there is 
a translation of the original version of the questionnaire and it is recommended that future research be included in these two categories analysis.

Given that self-assessment of teamwork efficiency is reversed information managers and clients, the assumption is that the examination is self-assessment should be done once the team members receive annual business reports. Insight the objective indicators of the work force would have influenced the more criticality of team members when analyzing teamwork.

\section{CONCLUSION?}

By analyzing the work efficiency of the compliant teams of the Service Department the companies of the Privredna banka in Zagreb found that the teams did not differ statistically significant in the overall outcome of the Teamwork Efficiency Questionnaire ( $? 2=3.473, \mathrm{df}=3, \mathrm{p}>0.05)$ as well as by categories of questionnaire $(? 2$ synergy $=2.062, \mathrm{df}=3, \mathrm{p}<0.05$; ? 2 skills $=5.843, \mathrm{df}=3, \mathrm{p}>0.05 ;$ ? 2 innovation $=2.300, \mathrm{df}=3, \mathrm{p}>0.05 ;$ ? 2 quality $=4.669, \mathrm{df}=3, \mathrm{p}>0.05$ ) and there is no confirmed hypothesis that teams will differ in self-assessments. According to the overall result self-assessment is seen to be average the ratings of the members of each team ranged from 3.35 to 3.98 , which indicates that the members of the team are their teams are evaluated more efficiently.

As a measure of the work of these teams, the evaluation of their clients was taken about the satisfaction of the service they receive from a particular team. Determined difference between the two to the teams according to the overall result of service satisfaction estimates did not show statistically significant $(F=2.424, d f=3 / 79, p>0.05)$, so no hypothesis that Teams will differentiate according to their clients' estimates. Estimates of individual clients Teams ranging from 3.094 to 4.312 show a high level of satisfaction with the service earned by teams in Privredna banka, and hence high work efficiency evaluated teams. Teams are equally evaluated by their clients and by categories of customer satisfaction survey questions. It is determined that the clients statistically significant lower ratings are given in the "trust" questionnaire category relative to other categories of questionnaire.

Based on the results of previous research, it was thought to be self-assessment

The team's work efficiency efficiency will be consistent with service satisfaction estimates of their clients, which partially and confirmed. The statistical analysis of the results showed is that teams statistically do not differ by self-assessments of work efficiency as well as their clients' estimates (which were taken as a measure of their work) efficiency), but comparing Figure 1 and Figure 3 there is a similar trend in the relationship between the mouse team results so that team $C$ in both questionnaires has the lowest score, while teams $A$ and $D$ they have high scores both in self-assessment and in customer evaluation. This is considered it is justified to confirm the hypothesis that there will be conformity self-assessment work teams' effectiveness and the evaluation of their clients.

\section{Literature}

[1] Adsit, J. D., London, M., Crom, S. and Jones, D. (1996): Relationships between

[2] employee attitudes, customer satisfaction and departmental performance. Journal of Management, Vol. 15, No.1, 62-75

[3] Blanchard, R.F. and Galloway, R.L. (1994): Quality in retail banking. International Journal of Service Industry Management. Vol. 5, No. 4, 5-23 3) Bateman, B., Wilson C.F and Bingham, D. (2002): Team Effectiveness development of an audit questionnaire. Journal of Management Developement, Vol. 21, No. 3, 215-226

[4] Churchill, G. A. Jr. and Peter, P.J. (1995): MARKETING - Creating value for

[5] customers. Irwin \& Austen Press

[6] Draft, R. (2000): MANAGEMENT. The Dryden Press, Orlando 6) Gilbert, R. (2000): Measuring internal customer satisfaction. Managing Service Quality, Vol. 10, No. 3, 178-186

[7] Guzzo, R. A., Yost, P.R., Cmpbell, R.J., and Shea, G.P. (1993): Potency in

[8] groups: Articulating a construct. British Journal of Social Psychology, 32, 87- 106

[9] Guzzo, R. A. and Dickson M.W. (1996): TEAMS IN ORGANIZATION: Recent 
[10] research on performance and effectiveness. Annual Review of Psychology, 47, 307-338

[11] Ingram, H., Teare, R., Scheuing, E. and Armistead, C. (1997): A system model of

[12] effective teamwork. The TQM Magazine, Vol. 9, No. 2, 118-127

[13] Newman, K. (2001): Interrogating SERVQUAL: A Critical Assessment of

[14] service quality measurement in a high street retail bank. International Journal of

[15] Bank, 19/3, 126-139

[16] Petz, B. (1985): Psychology of Work. Školska knjiga, Zagreb

[17] Ana Kuni? I? -Posinkovi ?: ANALIZA ISTRAŽIVANJA DJELATNOSTI 42

[18] Petz, B. (1992): Psychological Dictionary. Prosvjeta, Zagreb

[19] Prichard, J. S. and Staton N. A. (1999): Testing Belbin's team role theory of effective groups. The Journal of Management Development, Vol. 18, No. 8 652-665

[20] Robbins, S.P. (1992): Essential Elements of Organizational Behavior. Mate, Zagreb

[21] Rot, N. (1983): Psychology Group. Department for Textbooks and Teaching Resources, Belgrade

[22] Sikavica, P. and Novak, M. (1999): Business organization. Informator, Zagreb

[23] Storge, A. (2002): ORGANIZATION. Thomson Learning

[24] Tudor, G. and Sri, V. (1998): Manager and winning team. MEP Consult i Croman, Zagreb

[25] Vraneševi ?, T. (1996): Managing Customer Satisfaction. Golden Marketing, Zagreb

[26] Yancey, M. (1998): Work teams: three models of effectiveness. Center for

[27] study of work teams, University of North Texas

[28] West, M. A., Borrill, C.S. and Unsworth, K.L. (1998): Team effectiveness in

[29] organizations. International Review of Industrial and Organizational Psychology, Vol. 13, 1-48

[30] Wisniewski, M .: Using SERVQUAL to asses customer satisfaction with public

[31] sector services. Managing Service Quality, Vol.11, No. 6, 2001, 380-388 